\title{
Pentalogy of Cantrell associated with exencephaly and spinal dysraphism: antenatal ultrasonographic diagnosis. Case report.
}

\author{
Manohar B. Kachare ${ }^{1}$,Vinayak K. Patki ${ }^{2}$, Sonali S. Saboo ${ }^{3}$, Suresh H. Saboo ${ }^{3}$, Kulbir Ahlawat ${ }^{4}$, \\ Sachin S. Saboo 5
}

${ }^{1}$ Department of Radiology, Bharati Vidyapith Medical College, Sangli, Maharastra, India, ${ }^{2}$ Department of Pediatrics, Wanless Hospital, Miraj, Maharastra, India, ${ }^{3}$ Department of Radiology, Sai Diagnostic Center, Jalna, Maharastra, India, ${ }^{4}$ Department of Radiology, Medanta, The Medicity Hospital, Gurgaon, India, ${ }^{5}$ Department of Radiology, Brigham and Women's Hospital \& Harvard Medical School, Boston, USA

\begin{abstract}
The pentalogy of Cantrell, a rare syndrome, consists of the defects in the anterior diaphragm, diaphragmatic pericardium, lower sternum and supraumbilical abdominal wall, along with congenital cardiac abnormalities. Till date, only few patients with full spectrum of this syndrome have been reported with only 2 cases showing associated exencephaly and spinal dysraphism. We report extremely rare association of complete pentalogy of Cantrell syndrome with exencephaly and spinal dysraphism on antenatal sonogram and autopsy in a 18 weeks fetus of a 19 year-old primi gravida female.

Keywords: pentalogy of Cantrell, ultrasonography, prenatal diagnosis, exencephaly, spinal dysraphism
\end{abstract}

\section{Introduction}

The pentalogy of Cantrell is a rare congenital syndrome consisting of telltale features of omphalocele associated with ectopia cordis. However its full spectrum consists of five anomalies: anterior diaphragm deficiency, defect in the diaphragmatic pericardium, lower sternum and midline supraumbilical abdominal wall, along with various congenital cardiac abnormalities. The full spectrum of pentalogy of Cantrell has been described in few patients; moreover the association of pentalogy of Cantrell with combined exencephaly and spinal dysraphism is even rare and to our knowledge only 2 cases have been reported [1]. We report combined antenatal ultrasonographic and postmortem findings of a rare case of pentalogy of Cantrell associated with exencephaly along with spinal dysraphism diagnosed in a fetus of a 19 year-old primi gravida female.

Received 02.05.2013 Accepted 26.05.2013

Med Ultrason

2013, Vol. 15, No 3, 237-239

Corresponding author: Sachin S. Saboo, MD, FRCR

Brigham and Women's Hospital

Harvard Medical School

Boston, MA-02115, USA

Tel.: 617-817-9353, Fax: 857-307-2011

Email: ssaboo@partners.org

\section{Case Report}

A 19-year-old primigravida, nullipara women with first degree consanguineous marriage presented to the ultrasound unit for a routine anatomic scan at 18 weeks. Sonographic examination (Elegra, $3.5 \mathrm{MHz}$ convex transducer; Siemens Medical Solutions USA, Inc., Malvern, Pa., USA) revealed single live fetus with a femur length of 18 weeks and 4 days corresponding to the menstrual age. Additional sonographic findings included dysmorphic fetus face and absent fetal calvarial bones resulting in exposure of the brain parenchyma to the amniotic fluid consistent with exencephaly (fig 1a). Sonogram also revealed midline defect in lower chest and upper anterior abdominal wall, anterior diaphragm as well as defect in the sternum of the fetus with resultant evisceration of heart (ectopia cordis), along with liver, small and large bowel loops in the amniotic cavity (fig 1b,c). Small membanous VSD (fig 1b) and polyhydramnios were noted. Fetal spine revealed kyphoscoliotic deformity with spina bifida in lumbar region. The gynecologist and pediatric surgeon discussed the prognosis of the pregnancy with the patient and decision to terminate the pregnancy was taken before viability. All the above sonogram findings were confirmed in the autopsy specimen of the abortus (fig 2). 


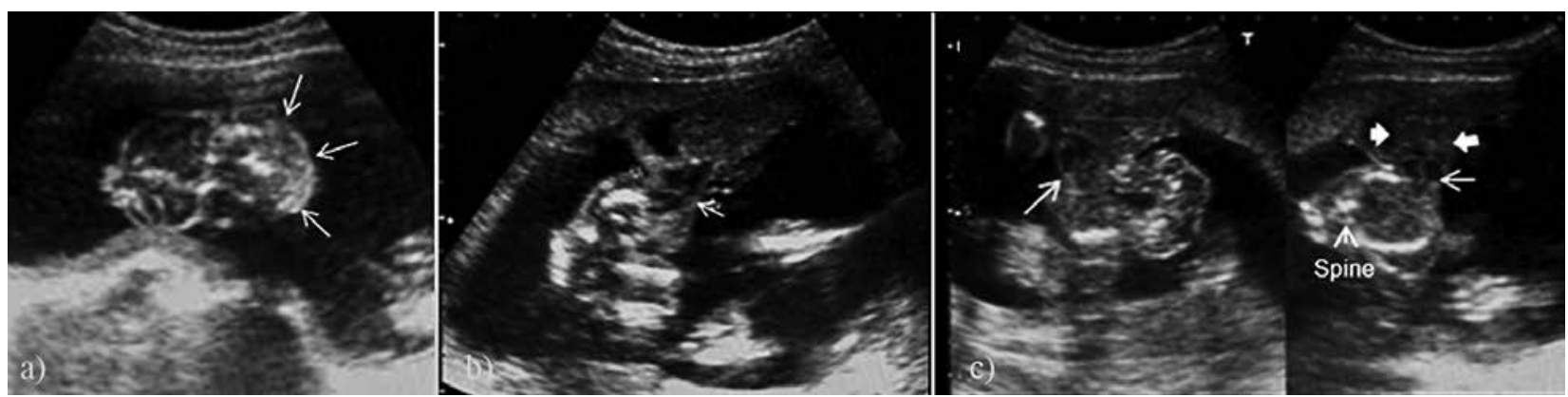

Fig 1. Transabdominal sonogram of the fetus: a) coronal view of fetal skull reveals absence of the flat bones of the calvarium with exposed brain parenchyma (exencephaly) (arrows); b) oblique image of the fetus reveals defect in the lower sternum with ectopia cordis (arrow); c) axial image of the fetus body showing defect in the lower chest and upper abdomen of the fetus with ectopia cordis (thin arrow), as well as external herniation of liver, spleen and bowel loops (bold arrows).

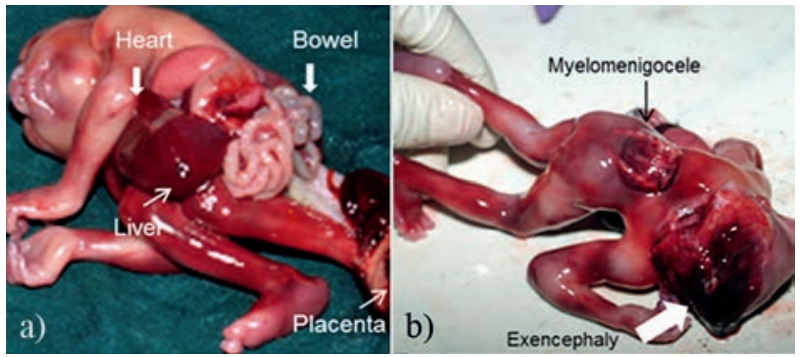

Fig 2. a) Anterior oblique specimen photographic view of the fetus on autopsy revealing defect in the lower chest and upper abdominal wall with ectopia cordis, and omphalocele containing herniated liver, spleen and bowel loops; b) Posterior photographic view of the fetus on autopsy revealing lumbar myelomeningocele and exencephaly.

\section{Discussion}

The pentalogy of Cantrell, a rare congenital syndrome characterized by ventral diaphragmatic hernia and omphalocele was intially described by Cantrell in 1958 [2]. This syndrome with poor prognosis consists of the following five anomalies: 1) deficient anterior diaphragm, 2) defect in the diaphragmatic pericardium, 3) lower sternal defect, 4) midline supraumbilical abdominal wall defect and 5) congenital cardiac abnormalities. The telltale signs of this syndrome are ectopia cordis and omphalocele [1]. VSD is the most common intracardiac finding while other common cardiac anomalies include ASD and tetralogy of Fallot. This syndrome has prevalence varying between 1:65,000 to $1: 200,000$ births $[3,4]$. Although, the pathogenesis is not clear, developmental failure of a segment of the lateral mesoderm and subsequent septum transversum in first month has been hypothesized as an underlying etiology [5].
Toyama classified this syndrome into three classes based on certainty of diagnosis as follows: 1) Diagnosis certain with complete syndrome and all five defects present; 2) Probable syndrome with four defects (including intracardia and anterior abdominal wall defect) present; and 3) Incomplete syndrome having variable combinations of defects (however always include an abnormal sternum) [3]. Ten cases of the pentalogy of Cantrell reported in the literature had central nervous system and craniofacial malformations; five of which had associated exencephaly and only 2 of these had spinal dysraphism $[1,6]$. Our case was a complete syndrome of pentalogy of Cantrell with additional findings of exencephaly and myelomeningocele.

The pentalogy of Cantrell can be usually diagnosed in the first trimester of pregnancy with antenatal sonogram [7] and should be ruled out in any fetus with omphalocele or ectopia cordis [5]. Moreover, the presence of pericardial effusion on antenatal sonogram should raise suspicion for associated anterior diaphragmatic hernia and diaphragmatic-pericardial defects and hence meticulous search for the features of the pentalogy of Cantrell should be considered [8]. Sonologist should be aware of the differential diagnosis of ectopia cordis which includes isolated thoracic ectopia cordis, amniotic band syndrome associated ectopia cordis, and the body-stalk anomaly syndrome [1].

Prenatal magnetic resonance imaging (MRI) may aid in better visualization of the fetal anomalies by better delineation of the herniation of fetal organs along with margins of the sternal and diaphragmatic defects in patients with pentalogy of Cantrell [9]. Cardiac abnormalities can be better evaluated with combination of MRI along with fetal echocardiography. This information can be helpful for pediatrician and surgeons to suggest prognosis and for preoperative planning especially in the era of devel- 
oped fetal surgical teams. However MRI can be limited from fetal motion artifacts [9].

The treatment of the pentalogy of Cantrell is mainly palliative consisting of correction of ventral hernia and diaphragmatic defects and correction of associated anomalies, with the important factors for deciding the appropriate treatment strategy being size of the ectopia cordis, abdominal wall defect and the associated cardiac anomalies [5]. Review of 58 cases of pentalogy of Cantrell in last twenty years revealed death of 37 fetuses suggesting grave prognosis especially in patients with the complete form of pentalogy of Cantrell, ectopia cordis, and those with associated other fetal anomalies [5].

In conclusion, we have shown antenatal sonographic and corresponding autopsy findings of an extremely rare association of classic pentalogy of Cantrell with exencephaly and myelomeningocele. It is important for sonologist to be cognizant that these anomalies can occur concurrently with the classic anomalies of the pentalogy of Cantrell on antenatal ultrasonogram inorder to facilitate better patient care.

\section{References}

1. Polat I, Gül A, Aslan H, et al. Prenatal diagnosis of pentalogy of Cantrell in three cases, two with craniorachischisis. J Clin Ultrasound 2005; 33: 308-311.
2. Cantrell JR, Haller JA, Ravitch MM. A syndrome of congenital defects involving the abdominal wall, sternum, diaphragm, pericardium, and heart. Surg Gynecol Obstet 1958;107:602-614.

3. Toyama WM. Combined congenital defects of the anterior abdominal wall, sternum, diaphragm, pericardium, and heart: a case report and review of the syndrome. Pediatrics 1972; 50: 778-792.

4. Rodgers EB, Monteagudo A, Santos R, Greco A, TimorTritsch IE. Diagnosis of pentalogy of Cantrell using 2- and 3-dimensional sonography. J Ultrasound Med 2010; 29: 1825-1828.

5. van Hoorn JH, Moonen RM, Huysentruyt CJ, van Heurn LW, Offermans JP, Mulder AL. Pentalogy of Cantrell: two patients and a review to determine prognostic factors for optimal approach. Eur J Pediatr 2008; 167: 29-35.

6. Denath FM, Romano W, Solcz M, Donnelly D. Ultrasonographic findings of exencephaly in pentalogy of Cantrell: case report and review of the literature. J Clin Ultrasound 1994; 22: 351-354.

7. Liang RI, Huang SE, Chang FM. Prenatal diagnosis of ectopia cordis at 10 weeks of gestation using two-dimensional and three-dimensional ultrasonography. Ultrasound Obstet Gynecol 1997; 10: 137-139.

8. Siles C, Boyd PA, Manning N, Tsang T, Chamberlain P. Omphalocele and pericardial effusion: possible sonographic markers for the pentalogy of Cantrell or its variants. Obstet Gynecol 1996; 87: 840-842.

9. McMahon CJ, Taylor MD, Cassady CI, Olutoye OO, Bezold LI. Diagnosis of pentalogy of cantrell in the fetus using magnetic resonance imaging and ultrasound. Pediatr Cardiol 2007; 28: 172-175. 